\title{
СИНТЕЗ ГРАФТ-СОПОЛИМЕРОВ КАРБОКСИМЕТИЛЦЕЛЛЮЛОЗЫ С $N$-ВИНИЛИМИДАЗОЛОМ И ИССЛЕДОВАНИЕ КИНЕТИКИ ВЫСВОБОЖДЕНИЯ ПРОТИВООПУХОЛЕВОГО ПРЕПАРАТА ПАКЛИТАКСЕЛ ИЗ АССОЦИАТА С СОПОЛИМЕРОМ
}

\author{
() 2018 В. А. Кузнецов, М. С. Лавлинская, А. В. Сорокин, Д. В. Быковский
}

Воронежский государственный университет, Университетская пл., 1, 394018 Воронеж, Россия

e-mail:dr.v.kuznetsov@gmail.com

Поступила в редакцию 24.07.2018

\begin{abstract}
Аннотация. Графт-сополимеры карбоксиметилцеллюлозы получены радикальной полимеризацией в растворе в присутствии перекиси водорода. Сополимеры охарактеризованы методами ИК- УФ-спектороскопии, гель-проникающей хроматографией и статическим светорассеянием. Изучение водных растворов сополимеров методами динамического светорассеяния, лазерного допплеровского микроэлектрофореза и просвечивающей электронной микроскопии показало, что частицы сополимеров имеют несферическую форму и характеризуются совокупным отрицательным зарядом частиц. Установлено, что взаимодействие между частицами сополимеров и Паклитакселом в водном растворе носит физический характер. Кинетика высвобождения препарата из комплекса с сополимером описывается кинетической моделью Корсмейера-Пеппаса и не подчиняется законам Фика.
\end{abstract}

Ключевые слова: графт-сополимеры, кинетика высвобождения, Паклитаксел.

DOI: https://doi.org/10.17308/kcmf.2018.20/576

\section{ВВЕДЕНИЕ}

Создание новых форм лекарственных препаратов селективного действия является одним из важнейших направлений современной биомедицины. Такие системы должны соответствовать требованиям современной медицины, а именно, быть биосовместимыми, биодеградируемыми, а также способными выделять действующее вещество непосредственно в пораженную область. Одним из перспективных материалов для создания систем адресной доставки являются модифицированные полимеры, отвечающие поставленным требованиям и способные к образованию устойчивых комплексов с действующим веществом. Особенно акутально применение подобных лекарственных форм в терапии опухолевых заболеваний. Традиционно используемые для такого лечения препараты - цитостатики - токсичны и оказывают губительное действие на весь организм в целом. Применение в качестве инертного носителя цитостатиков находит коммерчески доступное производное целлюлозы - натриевая соль карбоксиметилцеллюлозы - в виде концентрированного водного раствора. Стоить отме- тить, что такие растворы обладают ярко выраженным противоспаечным эффектом при их нанесении в ходе оперативного вмешательства [1].

Модификация полимера карбоксиметилцеллюлозы веществами, способными не только к повышению комплексообразования с действующим веществом, но и обладающими некоторой биологической активностью, позволяет расширить спектр применения лекарственных форм на основе этого полимера. Так, например, сополимер карбоксиметилцеллюлозы и $N$-винилимидазола обладает лучшими комплексообразующими свойствами по сравнению с соответствующими гомополимерами за счет присутствия различных типов функциональных групп. Благодаря наличию стерически доступного «пиридинового» атома азота $N$-винилимидазол обладает способностью к образованию комплексов с различными веществами, в том числе с цитостатиками. Помимо этого, введение звеньев $N$-винилимидазола в макромолекулу придает ей биологическую активность. Стоит отметить, что жесткоцепная структура карбоксиметилцеллюлозы и пространственное расположение привитых 
цепей в графт-сополимере повышает стерическую доступность функциональных групп и увеличивает вероятность образования комплекса сополимера и действующего вещества [2-4].

Одним из широко используемых препаратов для терапии раковых заболеваний репродуктивной системы является Паклитаксел. Механизм его действия, как и для прочих цистатиков, связан с нарушением процесса деления клетки. Однако данный препарат помимо большого количества преимуществ, таких как относительно невысокая цена и эффективность лечения, имеет ряд недостатков, одним из которых является необходимость длительного инфузионного введения. Возможным путем решения этой проблемы является использование новых лекарственных форм, созданных на основе полимерных частиц. Известно, что подобные формы не только способствуют снижению токсичности препарата, но и пролонгируют его действие за счет распада во времени комплекса полимер - Паклитаксел [5-6].

В связи с чем, цель нашей работы - синтез графт-сополимеров карбоксиметилцеллюлозы (Na-CMC) с $N$-винилимидазолом (VI), исследование их взаимодействия с противораковым препаратом Паклитаксел и изучение кинетики высвобождения лекарственного препарата из комплекса с сополимером.

\section{ЭКСПЕРИМЕНТАЛЬНАЯ ЧАСТЬ}

В работе использовались натриевая соль карбоксиметилцеллюлозы (КМЦ) с молекулярной массой $M_{\mathrm{w}}=20000$ и товарный мономер $N$-винилимидазол (ВИ) (все Sigma Aldrich, Германия) характеризуется $T_{\text {кип }}=78-79{ }^{\circ} \mathrm{C} / 11$ мм рт. ст.; $\rho=1.0382 \Gamma / \mathrm{cm}^{3}\left(25^{\circ} \mathrm{C}\right) ; n_{\mathrm{D}}{ }^{20}=1.5338$, товарный мономер непосредственно перед синтезом перегоняли с добавлением ингибитора гидрохинона под ва- куумом, отбирая фракцию $64-66{ }^{\circ} \mathrm{C} / 2.5$ мм рт. ст., что отвечает литературным данным.

Синтез осуществлялся по следующей методике: в термостатируемый реактор, снабженный мешалкой, помещали навеску 1.0 г КМЦ и $50 \mathrm{~cm}^{3}$ дистиллированной воды. Выдерживали смесь при $25 \pm 2$ ${ }^{\circ} \mathrm{C}$ при перемешивании до полного растворения полимера. Затем вносили $10.0 \mathrm{~cm}^{3}$ пероксида водорода, спустя 15 минут рассчитанное количество ВИ (табл. 1). По истечению 3 часов реакционную массу помещали в стакан, содержащий 100 см$^{3}$ ДМФА, перемешивали. Выделившийся осадок отфильтровывали на воронке Бюхнера, промывали и сушили в вакуумном сушильном шкафу до постоянной массы. Выход продуктов находился в интервале 65-73 \%.

Состав сополимеров определялся методом ИК-спектроскопии, учитывая соотношение величин площадей под полосами поглощения, относящихся к колебаниям $>\mathrm{C}=\mathrm{O}$-групп КМЦ и $>\mathrm{C}=\mathrm{N}$ групп имидазольного цикла при 1744 и $1456 \mathrm{~cm}^{-1}$ соответственно. ИК-спектры получены на прибоpe Bruker Vertex 70 (Bruker Optics, Германия) с Фурье-преобразователем методом нарушенного полного внутреннего отражения в диапазоне частот $400-4000 \mathrm{~cm}^{-1}$.

Эффективность прививки (ЭП) рассчитывали по следующей формуле [7]:

$$
Э \Pi=\frac{m_{2}-m_{1}}{m_{1}} \times 100
$$

где $m_{1}$ и $m_{2}$ масса очищенного и высушенного графт-сополимера и масса Na-КМЦ, г, соответственно.

Молекулярные массы образовавшихся полимеров определяли методом гель-проникающей хроматографии с помощью хроматографического комплекса, состоящего из двух инертных изографических насосов «АКВИЛОН ВЭЖХ», устройс-

Таблица 1. Условия синтеза графт-сополимеров КМЦ-ВИ

[Table 1. Synthesis conditions of the Na-CMC- $g$-VI copolymers $\left(\left[\mathrm{H}_{2} \mathrm{O}_{2}\right]=4 \cdot 10^{-3} \mathrm{~mol} \cdot \mathrm{L}^{-1}, \mathrm{~T}=25^{\circ} \mathrm{C}, \tau=3\right.$ hours $\left.)\right]$

\begin{tabular}{|c|c|c|c|c|c|}
\hline \multirow{2}{*}{ No. } & $\begin{array}{c}\text { Количество КМЦ, г } \\
{[\text { Na-СМС, }]}\end{array}$ & \multicolumn{3}{|c|}{$\begin{array}{c}\text { Количество ВИ } \\
{[\mathrm{VI}]}\end{array}$} & $\begin{array}{c}\text { Выход, \% } \\
\text { [Yield, \%] }\end{array}$ \\
\cline { 3 - 6 } & & $\begin{array}{c}v, \text { моль } \\
{[v, \mathrm{~mol}]}\end{array}$ & $\begin{array}{c}m, \Gamma \\
{[m, \mathrm{~g}]}\end{array}$ & $\begin{array}{c}V, \text { мл } \\
{[V, \mathrm{~mL}]}\end{array}$ & \\
\hline 1 & 1.000 & 0.005 & 0.50 & 0.48 & 73 \\
\hline 2 & 1.000 & 0.010 & 1.00 & 0.96 & 74 \\
\hline 3 & 1.000 & 0.015 & 1.50 & 1.44 & 71 \\
\hline 4 & 1.000 & 0.030 & 3.00 & 2.88 & 78 \\
\hline 5 & 1.000 & 0.040 & 4.00 & 3.84 & 77 \\
\hline 6 & 1.000 & 0.050 & 5.00 & 4.80 & 79 \\
\hline
\end{tabular}


тва автоматического ввода образца «Jetchrom», детектора «VUV-25 Dual Wavelength VIS Detector» и колоночного модуля с термостатом колонок «АКВИЛОН TS10», колонки для ВЭЖХ С-18 150 мм × 4.6 мм $\times 5$ мкм «PATHFINDER NQ», петли инжектора 10 мкл, оснащенного программным обеспечением «Portlab 30X» с функцией управления перистальтическими насосами. В качестве подвижной фазы использовалась смесь воды и ацетонитрил, калибровали по полистирольным стандартам. Для подтверждения результатов молекулярную массу $M_{W}$ привитых цепей также определяли методом статического светорассеяния [8].

Электрокинетический потенциал (ל-потенциал) частиц полимера в водных растворах определяли с помощь лазерного капиллярного допплеровского микроэлектрофореза на приборе «Malvern Zetasizer Nano» (Malvern Instruments, Великобритания) в кюветах, оснащенных золотым электродом.

Данные по динамическому светорассеянию получали (ДСР) на модульном спектрометре динамического и статического рассеяния света PhotocorComplex (Фотокор, Россия) в кварцевых кюветах, оборудованном Не-Nе лазером мощностью 25 мВт и длиной волны $\lambda-632.8$ нм. Съемка осуществлялась под углом $90^{\circ}$ при $25^{\circ} \mathrm{C}$, время измерения составляло 120 секунд. Расчеты вели с использованием программного обеспечения DynaLS.

Для определения размера и формы полимерных частиц в растворах использовали просвечивающую электронную микроскопию (ПЭМ) на электронном микроскопе Libra 120 (Carl Zeiss, Германия). Перед проведением съемки раствор полимера по каплям наносили на медную пластину, покрытую формваром, высушивали в токе воздуха в течение минуты, избыток раствора удаляли промоканием. Затем наносили контрастный агент (1 \%-ный раствор ацетата уранила), промокали и сушили в токе воздуха.

Изучение кинетики высвобождения in vitro. Для изучения процесса высвобождения препарата были созданы две системы, имеющие характеристики, схожие с пораженной тканью организма: температура $38 \pm 2{ }^{\circ} \mathrm{C}$ и $\mathrm{pH} 5.5$ (ацетатный буфер) и 6.8 (фосфатный буфер). Растворы Na-CMC-g-VI

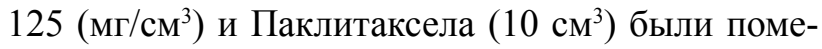
щены в градуированную трубку, разделенную на две секции с помощью целлюлозной мембраны, в верхней части раствор смеси, в нижней буфер. Для изучения кинетики высвобождения препарата из буферной части в течение 144 часов отбиралось по 1 мл, анализировалось с помощью спектроскопии.

\section{РЕЗУЛЬТАТЫ И ОБСУЖДЕНИЕ}

Сополимеры натриевой соли карбоксиметилцеллюлозы и $N$-винилимидазола с различным содержанием звеньев последнего получали радикальной полимеризацией в водном растворе в присутствии перекиси водорода. Инициирование протекало по окислительно-восстановительному механизму, где окислителем выступала перекись водорода, а восстановителем - пиранозные циклы КМЦ. Процесс проводили в мягких условиях, без нагревания, что, согласно литературным данным [9], должно приводить к образованию привитого сополимера. Продукты реакции выделяли трехкратным осаждением в ДМФА. Выбор осадителя обусловлен тем, что в нем растворяется Na-КМЦ и поли- и $N$-винилимидазол, что позволяет добиться очистки целевого продукта от побочных компонентов. Выход полученных продуктов лежит в интервале $71-79 \%$.

Структуру полученных продуктов подтверждали с помощью УФ- и ИК-спектроскопии. УФспектры водных растворов сополимеров содержат характеристические максимумы светопоглощения при 202 нм. Их присутствие подтверждает наличие винилимидазольных звеньев в макромолекулах, в то время как КМЦ не имеет собственного спектрального максимума. В ИК-спектрах водных растворов сополимеров $\mathrm{Na}-\mathrm{CMC}-\mathrm{g}-\mathrm{VI}$ присутствуют характеристические полосы поглощения в области 1100-1200 см ${ }^{-1}$, относящиеся к колебаниям полисахаридных фрагментов, $1456 \mathrm{~cm}^{-1}$, соответствующие колебаниям связи $\mathrm{C}=\mathrm{N}$ имидазольного цикла, $1744 \mathrm{~cm}^{-1}$, характерные для валентных колебания $\mathrm{C}=\mathrm{O}$ групп Na-КМЦ, колебания углеродного скелета поливинилимидазольной цепи при 2800 $2900 \mathrm{~cm}^{-1}$, также присутствует широкая полоса поглощения в области 3200-3300 cм $\mathrm{cm}^{-1}$, соответствующая колебаниям ОН-групп ассоциированных молекул воды. Составы сополимеров, определенные на основании спектральных данных, представлены в табл. 2.

Расчет эффективности процесса прививки позволил заключить, что в случае внесения небольших количеств ВИ (0.5-1.5 масс частей) практически весь мономер участвует в образовании графт-сополимера. С увеличением содержания ВИ в начальной полимеризационной смеси, и как следствие, повышением общей концентрации раствора, незначительно возрастает тенденция азолсодержащего мономера к гомополимеризации. Величины молекулярных масс привитых цепей поли- $N$-вини- 


\section{В. А. КУЗНЕЦОВ, М. С. ЛАВЛИНСКАЯ, А. В. СОРОКИН, Д. В. БЫКОВСКИЙ}

Таблица 2. Характеристика синтезированных графт-сополимеров

[Table 2. Characterization of the synthesized Na-CMC- $g$-VI copolymers]

\begin{tabular}{|c|c|c|c|c|c|c|c|}
\hline \multirow[b]{2}{*}{ No. } & \multirow{2}{*}{$\begin{array}{c}\text { Полимеризационная смесь, } \\
\text { Na-КМЦ:ВИ, } \\
\text { масс. частей } \\
\text { [Polymerization blend } \\
\text { Na-CMC:VI, w] }\end{array}$} & \multirow{2}{*}{$\begin{array}{c}\text { ВИ в сополимере, } \\
\% \text { масс } \\
{[\text { VI in copolymer, \% w] }}\end{array}$} & \multirow{2}{*}{$\begin{array}{l}\text { ЭП, \% } \\
{[\mathrm{GE},} \\
\%]\end{array}$} & \multicolumn{4}{|c|}{$\begin{array}{c}\text { Привитые цепи ПВИ } \\
\text { [PVI grafted chains] }\end{array}$} \\
\hline & & & & $\begin{array}{l}\mathrm{M}_{\mathrm{n}} \\
{\left[\mathrm{M}_{\mathrm{n}}\right]}\end{array}$ & $\begin{array}{l}\mathrm{M}_{\mathrm{w}} \\
{\left[\mathrm{M}_{\mathrm{w}}\right]}\end{array}$ & PDI & $\begin{array}{l}\mathrm{M}_{\mathrm{w}}^{*}{ }^{*} \\
{\left[\mathrm{M}_{\mathrm{w}}^{*}\right]}\end{array}$ \\
\hline 1 & $1: 0.5$ & 27 & 81 & 9896 & 10985 & 1.11 & 11103 \\
\hline 2 & $1: 1$ & 43 & 86 & 13542 & 15573 & 1.15 & 15264 \\
\hline 3 & $1: 1.5$ & 47 & 78 & 15678 & 17716 & 1.13 & 17803 \\
\hline 4 & $1: 3$ & 58 & 77 & 17542 & 20349 & 1.16 & 21085 \\
\hline 5 & $1: 4$ & 61 & 76 & 19452 & 21786 & 1.12 & 22723 \\
\hline 6 & $1: 5$ & 62 & 75 & 20103 & 22917 & 1.14 & 22869 \\
\hline
\end{tabular}

лимидазола (ПВИ), определенные методами ГПХ и статического светорассеяния, хорошо согласуются между собой и возрастают с увеличением концентрации мономера в исходной полимеризационной цепи (табл. 2). Стоит отметить, привитые цепи обладают довольно малым значением индекса полидисперсности (PDI) для продуктов, полученных в условиях радикального процесса.

Хорошо известно, что азольные циклы характеризуются склонностью к кислотно-основному взаимодействию за счет электронодонорных свойств «пиридинового» атома азота и электроноакцепторных свойств ненасыщенной $\pi$-системы [10]. В то же время, макромолекулы натриевой соли карбоксиметилцеллюлозы проявляют кислотные свойства. В связи с этим целесообразно изучить свойства водных растворов синтезированных графт-сополимеров.

Исследование зависимости размеров частиц макромолекул сополимеров в разбавленных водных растворах от содержания звеньев ВИ в боковых це- пях показало, что с их увеличением величина гидродинамического радиуса $R_{\mathrm{b}}$ возрастает незначительно (табл. 3). Одновременно с $R_{\mathrm{h}}$ возрастает и величина радиуса инерции $R_{\mathrm{g}}$, что свидетельствует об увеличении размеров частиц за счет большей длины боковых звеньев ВИ. Величина отношения $R_{\mathrm{g}} / R_{\mathrm{h}}$ показывает, что независимо от длины боковых цепей макромолекулярные клубки в растворе отклонены от сферической формы, что обусловлено влиянием жесткоцепным характером макромолекул КМЦ. Данные просвечивающей электронной микроскопии, представленные на рис. 1, подтверждают результаты, полученные с помощью динамического светорассеяния.

Одной из важнейших характеристик, определяющих устойчивость дисперсной системы, является величина электрокинетического потенциала. Из табл. 3 видно, что макромолекулярные клубки синтезированных сополимеров характеризуются совокупным отрицательным зарядом ( $\zeta$-потенциалом). С увеличением содержания звеньев ВИ в со-

Таблица 3. Свойства водных растворов сополимеров $\mathrm{Na}-\mathrm{CMC}-g$-VI

[Table 3. Properties of the water solutions of the Na-CMC-g-VI copolymers]

\begin{tabular}{|c|c|c|c|c|c|c|c|}
\hline No & $\begin{array}{c}\text { Содержание ВИ в сополимере, \% масс. } \\
{[\mathrm{VI} \text { in the copolymer, \% w }}\end{array}$ & $\begin{array}{c}R_{h}, \mathrm{HM} \\
{\left[R_{h}, \mathrm{~nm}\right]}\end{array}$ & $\begin{array}{c}R_{g}, \mathrm{HM} \\
{\left[R_{g}^{2}, \mathrm{~nm}\right]}\end{array}$ & $R_{g} / R_{h}$ & $\mathrm{pH}$ & $\begin{array}{c}\zeta, \mathrm{MB} \\
{[\zeta, \mathrm{mV}]}\end{array}$ & $\begin{array}{c}m_{e}, \text { мкмтсм/Bc } \\
{\left[m_{e}, \mu \mathrm{mcm} / \mathrm{Vs}\right]}\end{array}$ \\
\hline 1 & 27 & 120 & 178 & 1.48 & 6.86 & -45.1 & -3.312 \\
\hline 2 & 43 & 130 & 190 & 1.46 & 6.42 & -30.8 & -2.315 \\
\hline 3 & 47 & 141 & 210 & 1.49 & 6.40 & -17.2 & -1.350 \\
\hline 4 & 58 & 148 & 222 & 1.50 & 6.35 & -13.1 & -1.308 \\
\hline 5 & 61 & 149 & 219 & 1.47 & 6.35 & -10.2 & -1.241 \\
\hline 6 & 62 & 152 & 225 & 1.48 & 6.33 & -9.6 & -1.187 \\
\hline
\end{tabular}




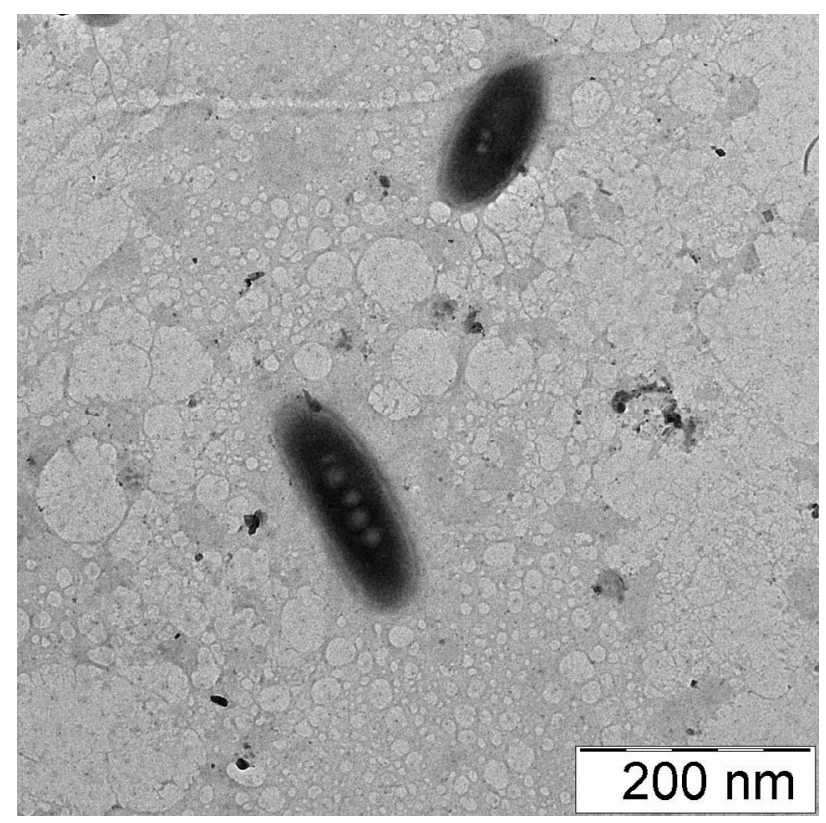

Рис. 1. ПЭМ-изображение частиц сополимера (62\% масс ВИ)

[Fig. 1. The TEM image of the copolymer particles (62\% w VI)]

полимере величина отрицательного заряда снижается, что объясняется компенсацией отрицательного заряда карбоксильных групп КМЦ положительно заряженными звеньями ВИ. На это же указывает значение объемной плотности заряда $m$, которое снижается с увеличением содержания звеньев ВИ. Следует отметить, что при содержании звеньев ВИ 27 и $43 \%$ масс растворы сополимеров относятся к сильно заряженным золям, а остальные - к слабо заряженным. Величины $\mathrm{pH}$ растворов сополимеров близки к нейтральному значению и лежат в интервале 6.33-6.86.

Паклитаксел - цитостатик широкого действия, используемый для противораковой терапии. Стоит отметить, что Паклитаксел гидрофобное вещество, для его инфузионного введения требуется создание лекарственных форм с поверхностными веществами, обеспечивающими его гидрофилизацию. Для эксперимента была использована коммерческая форма препарата Паклитаксел с этанолом и макрогол глицерилрицинолеат. Для отделения от этих веществ смесь Паклитаксела с Na-CMC-g-VI была диализована против дистиллированной воды.

На рис. 2 представлены УФ спектры водного раствора Паклитаксела и его смеси с раствором NaCMC-g-VI. Спектр противоопухолевого препарата содержит максимумы при 234 и 200 нм. Эти же максимумы светопоглощения присутствуют и в УФ спектре смеси, причем изменений в их положении

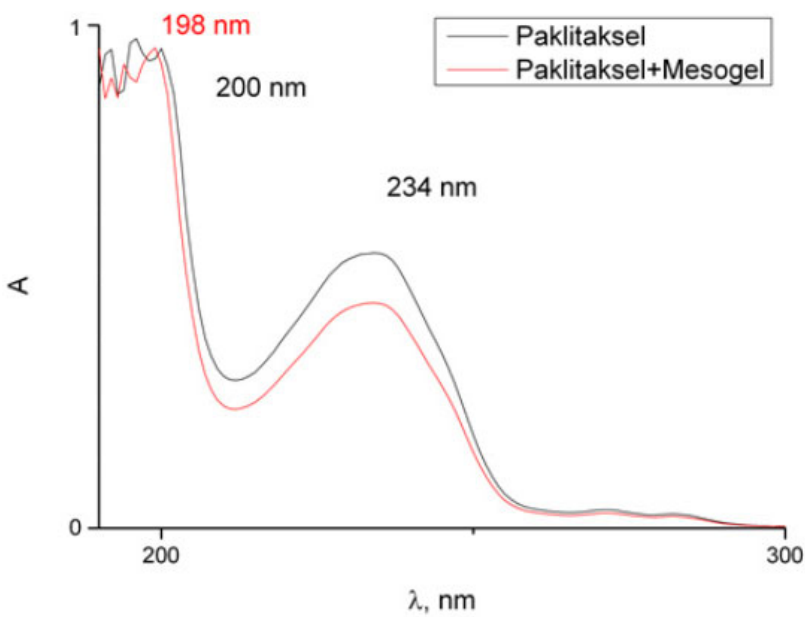

Рис. 2. УФ-спектры водных растворов Паклитаксела и сополимера

[Fig. 2. UV spectra of Ptx and copolymer aqueous solutions]

практически не наблюдается. Это свидетельствует об отсутствии ковалентного связывания между Паклитакселем и сополимером.

В ИК спектре водного раствора сополимера Na-CMC-g-VI (62 \% VI) (рис. 3) присутствуют характеристические полосы поглощения в области $1100-1200 \mathrm{~cm}^{-1}$, относящиеся к колебаниям полисахаридных фрагментов, $1456 \mathrm{~cm}^{-1}$, соответствующие колебаниям связи - $\mathrm{C}=\mathrm{N}$ - имидазольного цикла, $1744 \mathrm{~cm}^{-1}$, характерные для валентных колебания $>\mathrm{C}=\mathrm{O}$-групп КМЦ, колебания углеродного скелета поливинилимидазольной цепи при 2800-2900 cм также присутствует широкая полоса поглощения в области 3200-3300 cм ${ }^{-1}$, соответствующая колебаниям ОН-групп ассоциированных молекул воды. В ИК спектре Паклитаксела (рис. 4) содержатся полосы поглощения валентных колебаний эпокси-групп в области $1084 \mathrm{~cm}^{-1}$, валентные колебания ароматических колец и их СН-групп при1348-1455 $\mathrm{cm}^{-1}$ и $2870-2970 \mathrm{~cm}^{-1}, 1580 \mathrm{~cm}^{-1}$, отвечающая колебаниям вторичной амино-группы, интенсивная полоса поглощения при $1734 \mathrm{~cm}^{-1}$, относящаяся к валентным колебаниям $>\mathrm{C}=\mathrm{O}$-групп, и широкая полоса поглощения в области $3300 \mathrm{~cm}^{-1}$, относящаяся к валентным колебаниям ОН-групп водного раствора препарата. В спектре их смеси (рис. 3) присутствуют описанные выше полосы поглощения, их смещения практически не наблюдается. Только в случае полос поглощения при $744 \mathrm{~cm}^{-1}, 1456 \mathrm{~cm}^{-1}$, и 2800 $2900 \mathrm{~cm}^{-1}$ наблюдаются незначительные смещения. Это свидетельствует о дестабилизации ассоциации макромо-лекул КМЦ в водных растворах за счет внедрения молекул Паклитаксела, а также об об- 


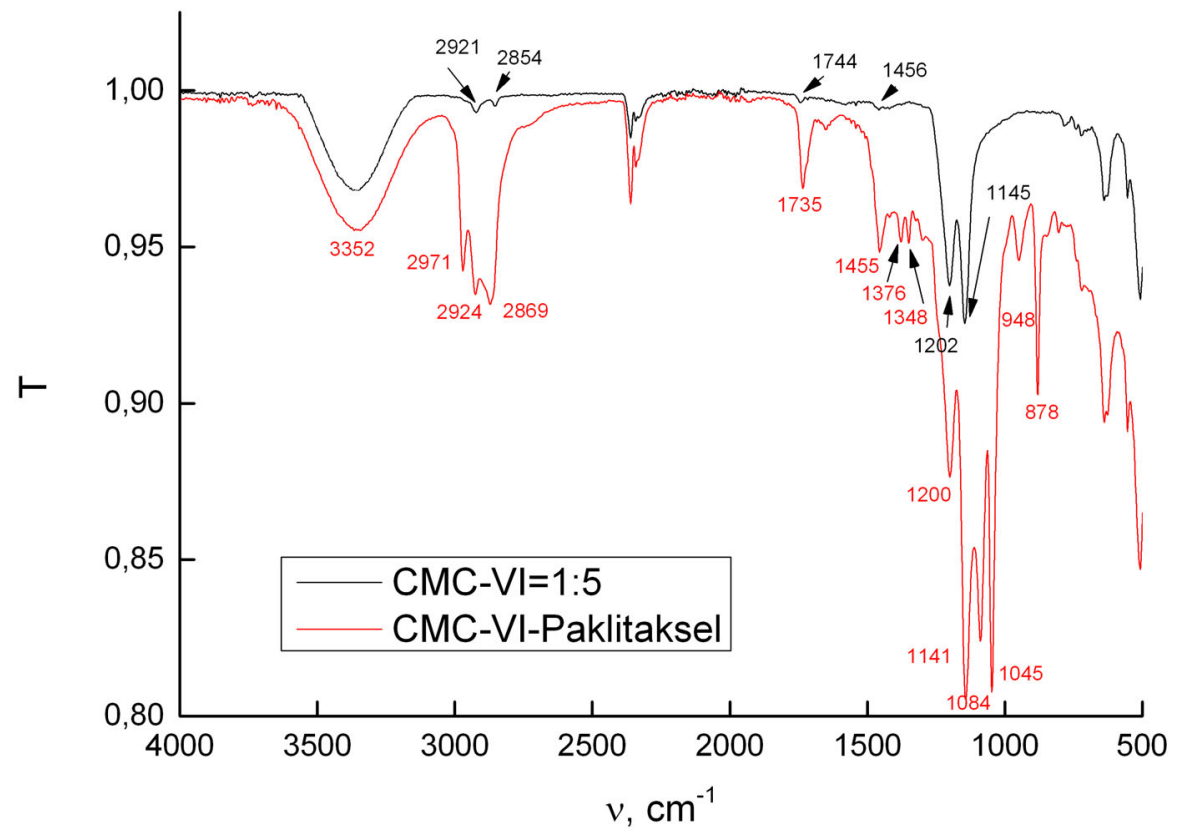

Рис. 3. ИК-спектр смеси сополимера с Паклитакселом

[Fig. 3. FTIR spectrum of Ptx and copolymer mixture]

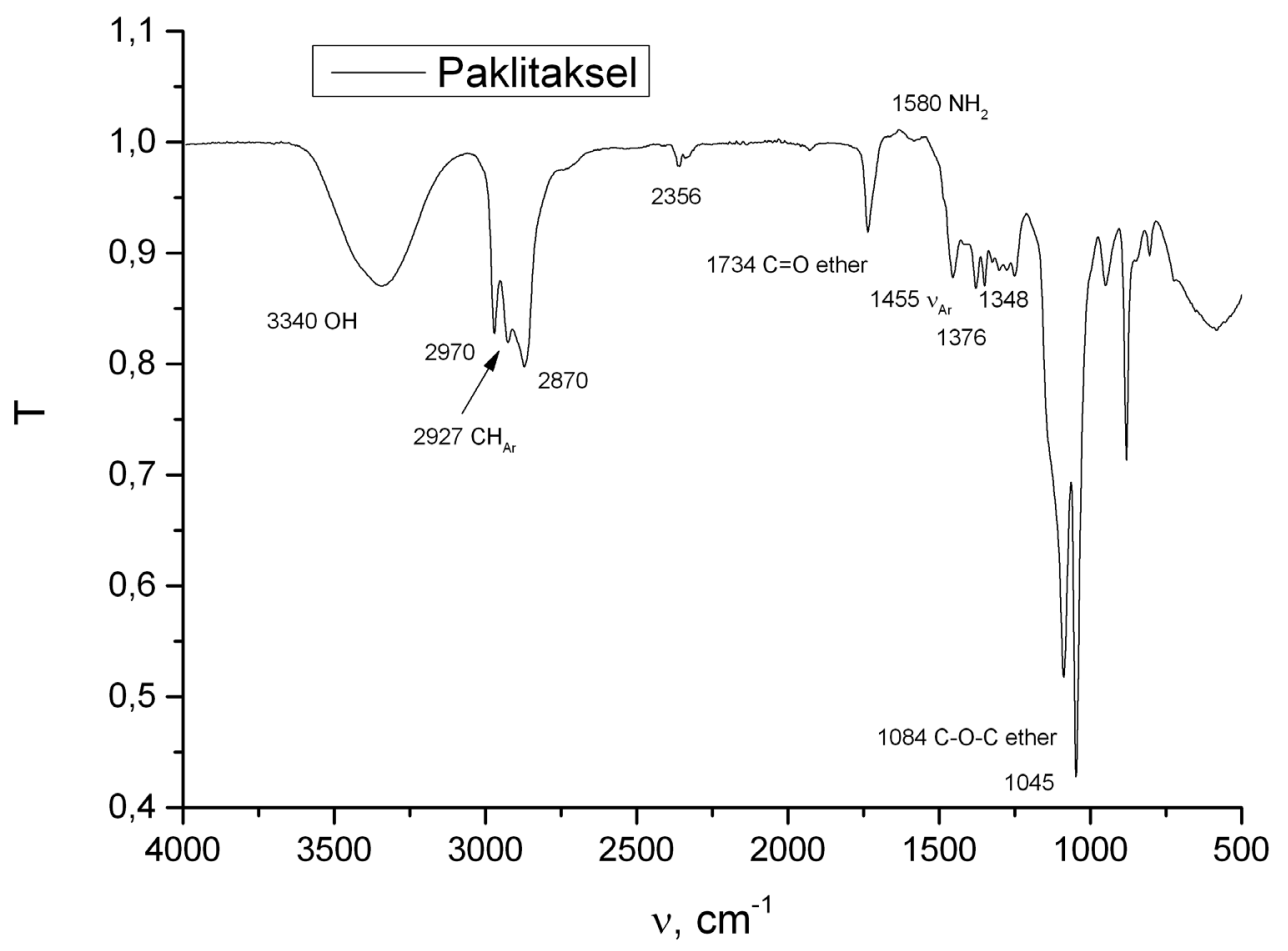

Рис. 4. ИК-спектр Паклитаксела

[Fig. 4. FTIR spectrum of Ptx] 
разовании ассоциата между полимерной матрицей и молекулами препарата посредством притяжения между частично отрицательно заряженными карбонильными группами препарата и азольными кольцами полимера, а также гидрофобных и стековых взаимодействиях. Данные ПЭМ (рис. 5) также подтверждают ассоциацию сополимера и Паклитаксела и сильный вклад гидрофобных взаимодействий в процесс комплексообразования.

Изучение кинетики высвобождения проводилось в буферных растворах при $\mathrm{pH}=5.5$ и 6.8 , при температуре $38^{\circ} \mathrm{C}$. Для изучения были выбраны графт-сополимеры с максимальным (62\%) и минимальным (27 \%) количеством ВИ в цепи. Кривые высвобождения паклитаксела представлены на рис. $6 a$ и $6 b$. Как видно из графиков, увеличение $\mathrm{pH}$ не имеет значительного влияния на процесс высвобождения препарата. В обоих случаях практически полное высвобождение Паклитаксела происходит в течение 144 часов. Высвобождение препарата происходит быстрее в случае использования $\mathrm{Na}-\mathrm{CMC}$ g-VI (27 \% VI). Это объясняется влиянием стерического фактора на высвобождение из комплекса Паклитаксела с графт-сополимером с максимальным содержанием ВИ в цепи.

Для определения механизма высвобождения Паклитаксела из комплекса для сополимера с массовым содержанием ВИ 27 \% и рН 5.5 были применены различные кинетические математические модели, такие как модель нулевого порядка, модель первого порядка и модель Корсмейера-Пеппаса (Korsmeyer-Peppas).

Модель нулевого порядка описывается уравнением:

$$
q_{t}=q_{0}+k_{0} t,
$$

где $q_{t}-$ количество высвободившегося препарата во время $t, q_{0}$ - начальное количество препарата в среде (обычно $=0), k_{0}$ - константа скорости высвобождения нулевого порядка.

Модель первого порядка имеет следующий вид:

$$
\ln \left(q_{t}\right)=\ln \left(q_{0}\right)-k_{1} t,
$$

где $q_{t}$ - количество высвободившегося препарата во время $t, q_{0}-$ начальное количество препарата в среде (обычно $=0), k_{1}$ - константа скорости высвобождения первого порядка.

Модель Корсмеера-Пеппаса:

$$
\frac{q_{t}}{q_{\infty}}=k_{\mathrm{KP}} t^{n}
$$

где $q_{t}-$ количество высвободившегося препарата во время $t, q_{\infty}$ - равновесная концентрация высво-

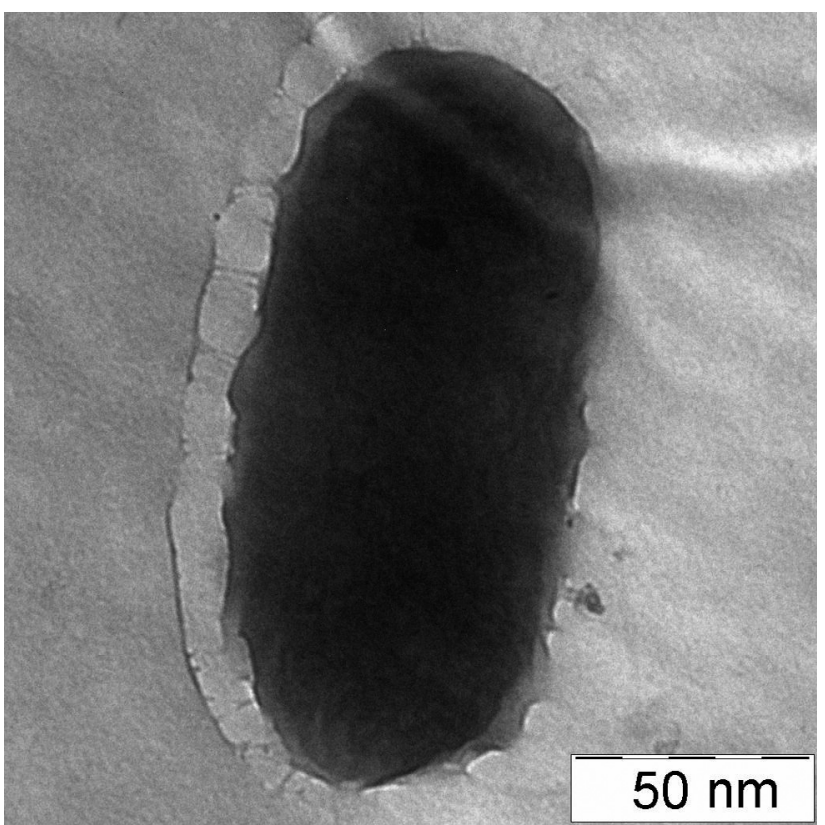

Рис. 5. ПЭМ изображение смеси сополимера с Паклитакселом

[Fig. 5. TEM image of the Ptx-copolymer blend]

бодившегося вещества. $k_{\mathrm{KP}}-$ константа скорости Корсмейера-Пеппаса, $n$ - кинетическая характеристика, определяющая механизм высвобождения вещества. При $n \leq 0.45$ высвобождение происходит согласно закону Фика, при $0.45<n<1$ процесс высвобождения не подчиняется закону Фика [11].

Кинетические параметры процесса высвобождения определены с помощью графических зависимостей, представленных на рис 6 . В табл. 4 представлены численные значения параметров для всех кинетических моделей в случае высвобождения из сополимера, содержащего $27 \%$ масс ВИ при $\mathrm{pH}=5.5$. Как видно из представленных данных, наиболее подходящей для описания процесса является кинетическая модель КорсмейраПеппаса (рис. 7). Из величины константы $n$ можно сделать вывод, что высвобождение не подчиняется законам Фика. Механизм может быть связан с процессом пластификации поверхности полимерных частиц, в результате чего происходит релаксация макроцепей, позволяющая высвободить препарат [12].

\section{ЗАКЛЮЧЕНИЕ}

Таким образом, получены графт-сополимеры натриевой соли карбоксиметилцеллюлозы с $N$-винилимидазолом. Установлено, что в водном рас- 
a
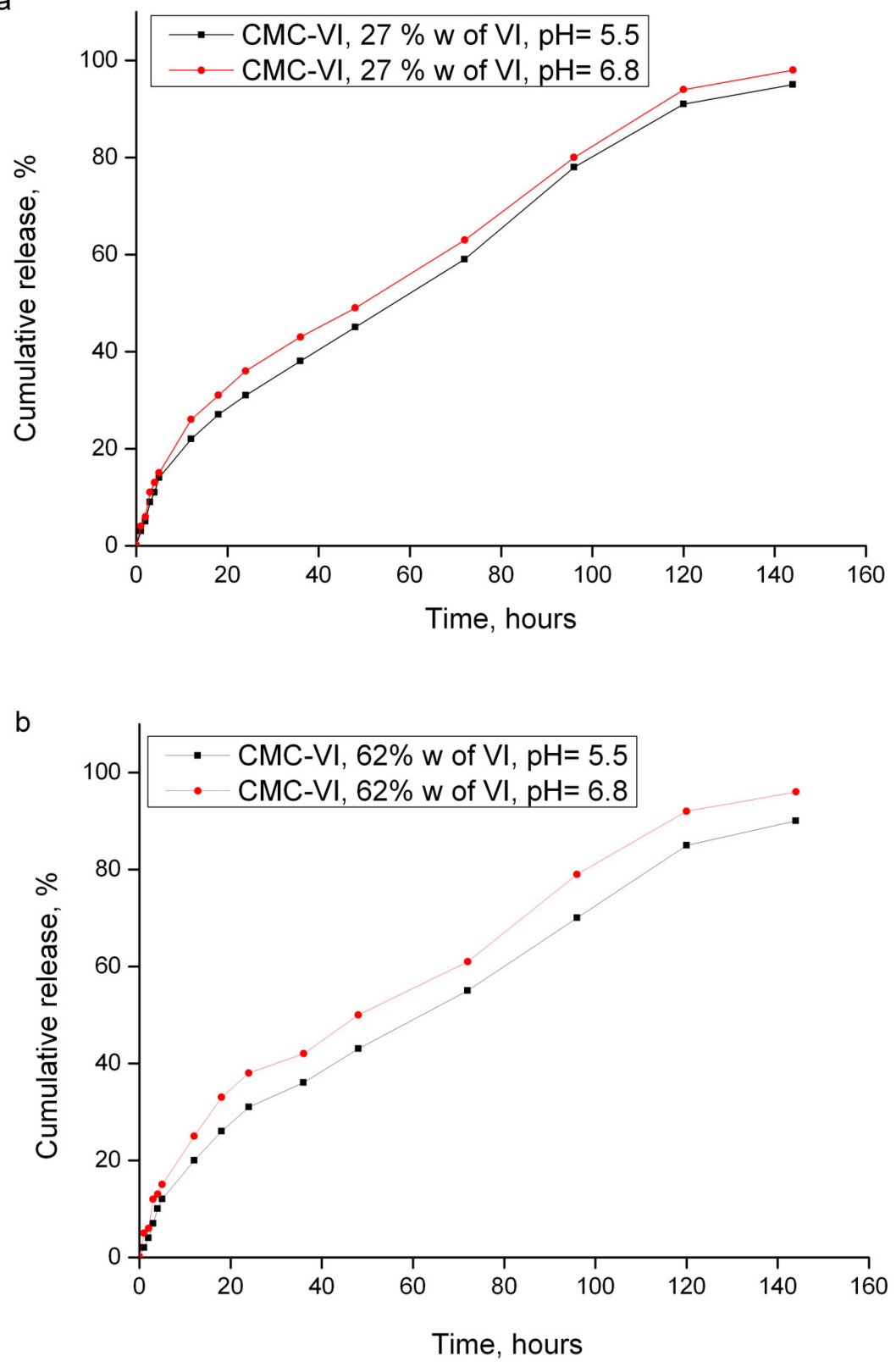

Рис. 6. Кривые высвобождения Паклитаксела из комплекса с сополимером [Fig. 6. Release curves of Ptx]

Таблица 4. Кинетические параметры высвобождения Паклитаксела из ассоциата с сополимером $\mathrm{Na}-\mathrm{CMC}-g$-VI с содержанием ВИ $27 \%$ масс при $\mathrm{pH} 5.5$

[Table 4. Kinetic parameters of Ptx release from Na-CMC-g-VI copolymers with $27 \% \mathrm{w}$ of VI at $\mathrm{pH} 5.5$ ]

\begin{tabular}{|c|c|c|c|}
\hline $\begin{array}{c}\text { Модель } \\
\text { [Model] }\end{array}$ & $k$ & $R^{2}$ & $n$ \\
\hline $\begin{array}{c}\text { Нулевой порядок } \\
\text { [Zero order] }\end{array}$ & 0.6249 & 0.9656 & - \\
\hline $\begin{array}{c}\text { Первый порядок } \\
\text { [First order] }\end{array}$ & 1.0623 & 0.6856 & - \\
\hline $\begin{array}{c}\text { Kopсмейера-Пеппаса } \\
\text { [Korsmeyer-Peppas model] }\end{array}$ & 0.1215 & 0.9839 & 0.6584 \\
\hline
\end{tabular}


a

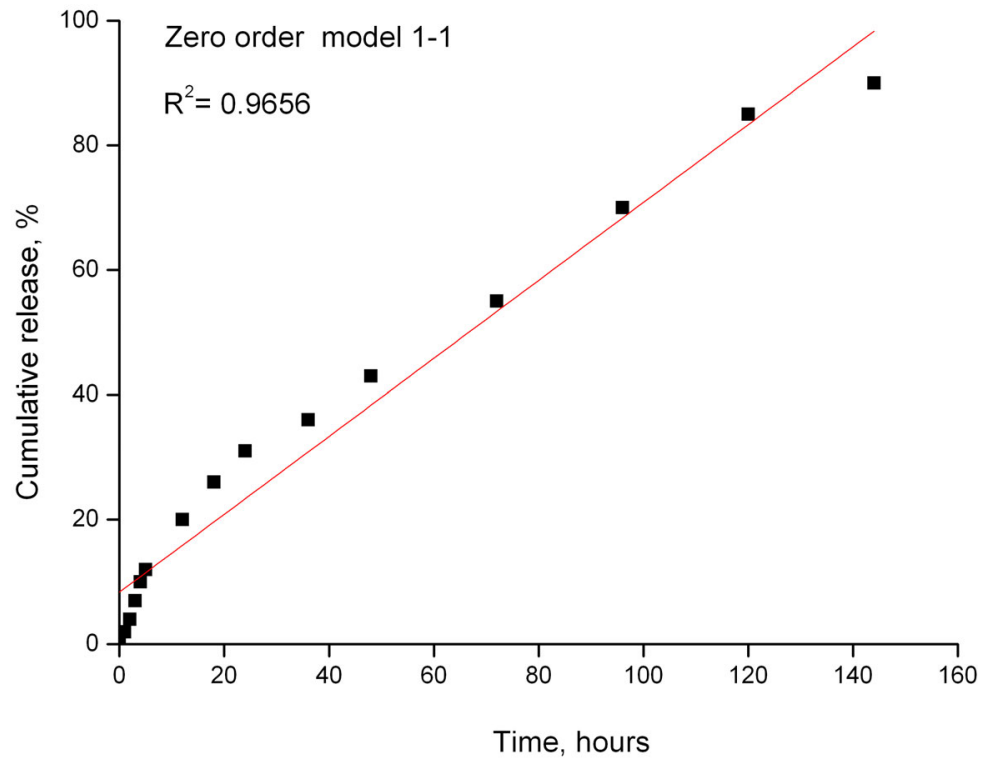

b

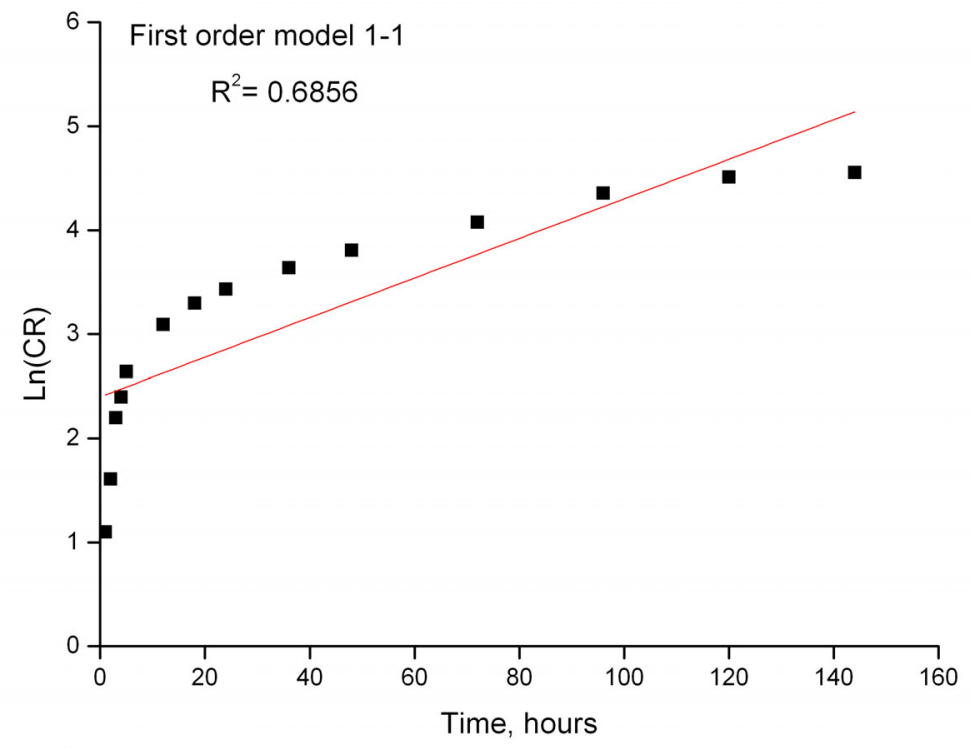

C

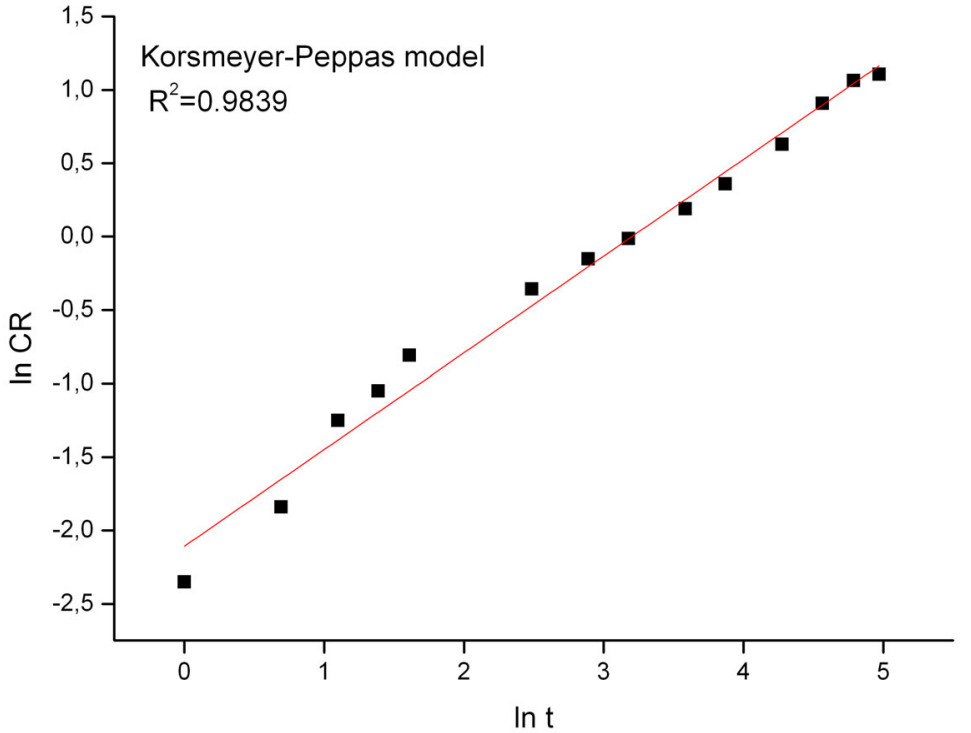

Рис. 7. Кинетические модели процесса высвобождения [Fig. 7. Kinetic release models] 
творе частицы сополимеров имеют несферическую форму и отрицательное значение электрокинетического потенциала. Изучение взаимодействия Паклитаксела с сополимерами в водном растворе позволило установить, что между ними не происходит химического взаимодействия, однако, происходит образование ассоциата за счет физических сил. Кинетика высвобождения препарата из его ассоциата изучена в условиях in vitro в диапазоне $\mathrm{pH}$ 5.5-6.8. Найдено, что величина $\mathrm{pH}$ в этих пределах не оказывает значительного влияния на скорость процесса, а процесс высвобождения описывается кинетической моделью Корсмейра-Пеппаса и не подчиняется законам Фика.

Данные ИК-спектроскопии, просвечивающей электронной микроскопии, лазерного допплеровского микроэлектрофореза получены на оборудовании Центра коллективного пользования научного оборудования ВГУ.

\section{СПИСОК ЛИТЕРАТУРЫ}

1. Bhattacharrya S. N., Misra B. N. Prog. Polym. Sci., 2004, vol. 13, pp. 768-769. DOI: DOI: $10.1016 / \mathrm{j}$. progpolymsci.2004.05.002

2. Madruga E. L. Prog. Polym. Sci., 2002, vol. 27, pp. 1879-1924. DOI: 10.1016/S0079-6700(02)00023-0
3. Oh J., Drumright R., Siegwart D., Matyjaszewski K. Prog. Polym. Sci., 2008, vol. 33, pp. 448-477. DOI: 10.1016/ j.progpolymsci.2008.01.002

4. Kuznetsov V. A., Lavlinskaya M. S., Ostankova I. V. Polym. Bull., 2018, vol. 75, pp. 1237-1251. DOI: $10.1007 /$ s00289-017-2091-2

5. Shin Y. M., Lim K. S., Jeong S. I., et al. Macromol. Res., 2009, vol. 17, pp. 1039-1042. DOI: 10.1007/ $\mathrm{BF} 03218654$

6. Ren P., Wu Y., Guo W., et al. Chin. J. Polym. Sci., 2013, vol. 31, pp. 285-293. DOI: 10.1007/s10118-0131216-9

7. Worzakowska M. J. Polym. Environ., 2018, vol. 26, pp. 1613-1624. DOI: 10.1007/s10924-017-1062-X

8. Kuznetsov V. A., Kushchev P. O., Blagodatskikh I. V. Colloid. Polym. Sci., 2016, vol. 294, pp. 889-899. DOI: 10.1007/s00396-016-3843-5

9. Genç F, Uzun C, Güven O. Polym. Bull., 2016, vol. 73, pp. 179-190. DOI: 10.1007/s00289-015-1479-0

10. Jakubiak-Marcinkowska A., Legan M., Jezierska J. J Polym Res, 2013, vol. 20, pp 317-328. DOI: 10.1007/ s10965-013-0317-z

11. Korsmeyer R. W., Gurny R., Doelker E. M., Buri P., Peppas N. A. Int. J. Pharm., 1983, vol. 15, pp. 25-35. DOI: 10.1016/0378-5173(83)90064-9

12. Llabot J. M., Manzo R. H., Allemandi D. A. Int $J$ Pharm, 2004, vol. 276, pp. 59-66. DOI: 10.1016/j. ijpharm.2004.02.006

\title{
SYNTHESIS OF THE CARBOXYMETHYL CELLULOSE AND $N$-VINYLIMIDAZOLE GRAFT-COPOLYMERS AND RELEASE INVESTIGATION OF ANTITUMOR DRUG PACLITAXEL FROM THE COPOLYMER ASSOCIATE
}

\author{
(C) 2018 V. A. Kuznetsov, M. S. Lavlinskaya, A. V . Sorokin D. V. Bykovskiy \\ Voronezh State University, 1 Universitetskaya pl., 394018 Voronezh, Russia \\ e-mail:dr.v.kuznetsov@gmail.com
}

Received 24.07.2018

\begin{abstract}
The goal of this work is synthesis of the sodium salt of carboxymethyl cellulose (Na-CMC) and $N$-vinylimidazole (VI) graft-copolymers (Na-CMC- $g$-VI), researching of the interaction between $\mathrm{Na}-\mathrm{CMC}-\mathrm{g}$-VI and antitumor drug Paclitaxel (Ptx), and release kinetics investigation of the latter from it copolymer associate. Na-CMC-g-VI water-soluble copolymers were obtained by free radical solvent copolymerization in a presence of hydrogen peroxide initiator. The structure of the synthesized copolymers was confirmed by FTIR. Properties of aqueous solutions of the Na-CMC-g-VI copolymers were researched via dynamic light scattering, transmission electron microscopy (TEM), and zetameasurement. Found that copolymer particles in the solutions are non-spheric macrochain agglomerates with hydrodynamics radii in a range $120-152 \mathrm{~nm}$ (Fig.1), and their surface possesses cumulative negative charge. Interaction between $\mathrm{Na}-\mathrm{CMC}-\mathrm{g}$-VI copolymers and Ptx was researched via UV spectroscopy (Fig. 2), FTIR (Fig. 3-4), and TEM (Fig. 5). Established that associate formation occurs by physical binding by hydrophobic and stacking interactions. In addition, carbonyl groups of Ptx and
\end{abstract}


imidazole cycles of VI grafted chain takes part in the interactions. Ptx release kinetics was researched by in vitro mode in a range of $\mathrm{pH}$ values $5.5-6.8$ at $38^{\circ} \mathrm{C}$. Changes of the $\mathrm{pH}$ values in the described region slightly effect on the release rate (Fig. 6). Different kinetic models were applied to describe the Ptx release process (Fig. 7). Found that Korsmeyer-Peppas kinetic model is the most appropriate model for researching systems, and release process characterized by «non-Fickian» diffusion. To sum up, Na-CMC- $g$-VI copolymers were synthesized, and their interaction with Ptx in aqueous solutions, as well as release kinetics of the latter from copolymer associate were investigated.

Keywords: graft copolymers, release kinetics, Paclitaxel.

DOI: https://doi.org/10.17308/kcmf.2018.20/576

\section{AKNOWLEDGMENTS}

FTIR, TEM, zeta-potential data were obtained with use of equipment of Center of collective usage of scientific equipment of Voronezh State University.

\section{REFERENCES}

1. Bhattacharrya S. N., Misra B. N. Prog. Polym. Sci., 2004, vol. 13, pp. 768-769. DOI: DOI: 10.1016/j.progpolymsci.2004.05.002

2. Madruga E. L. Prog. Polym. Sci., 2002, vol. 27, pp. 1879-1924. DOI: 10.1016/S0079-6700(02)00023-0

3. Oh J., Drumright R., Siegwart D., Matyjaszewski K. Prog. Polym. Sci., 2008, vol. 33, pp. 448-477. DOI: 10.1016/ j.progpolymsci.2008.01.002

4. Kuznetsov V. A., Lavlinskaya M. S., Ostankova I. V. Polym. Bull., 2018, vol. 75, pp. 1237-1251. DOI: 10.1007/ s00289-017-2091-2

5. Shin Y. M., Lim K. S., Jeong S. I., et al. Macromol. Res., 2009, vol. 17, pp. 1039-1042. DOI: 10.1007/ BF03218654
6. Ren P., Wu Y., Guo W., et al. Chin. J. Polym. Sci., 2013, vol. 31, pp. 285-293. DOI: 10.1007/s10118-0131216-9

7. Worzakowska M. J. Polym. Environ., 2018, vol. 26, pp. 1613-1624. DOI: 10.1007/s10924-017-1062-x

8. Kuznetsov V. A., Kushchev P. O., Blagodatskikh I. V. Colloid. Polym. Sci., 2016, vol. 294, pp. 889-899. DOI: 10.1007/s00396-016-3843-5

9. Genç F, Uzun C, Güven O. Polym. Bull., 2016, vol. 73, pp. 179-190. DOI: 10.1007/s00289-015-1479-0

10. Jakubiak-Marcinkowska A., Legan M., Jezierska J. J Polym Res, 2013, vol. 20, pp 317-328. DOI: 10.1007/ s10965-013-0317-z

11. Korsmeyer R. W., Gurny R., Doelker E. M., Buri P., Peppas N. A. Int. J. Pharm., 1983, vol. 15, pp. 25-35. DOI: 10.1016/0378-5173(83)90064-9

12. Llabot J. M., Manzo R. H., Allemandi D. A. Int $J$ Pharm, 2004, vol. 276, pp. 59-66. DOI: 10.1016/j. ijpharm.2004.02.006
Кузнецов Вячеслав Алексеевич - д. х. н., доцент, профессор кафедры высокомолекулярных соединений и коллоидной химии, Воронежский государственный университет; тел.: +7(920) 4523733; e-mail: dr.v.kuznetsov@gmail.com

Лавлинская Мария Сергеевна - к. х. н., м. н. с. базовой кафедры ЭФКО «Молекулярная биотехнология», Воронежский государственный университет; тел.: +7(950) 7585216; e-mail: maria. lavlinskaya@gmail.com

Сорокин Андрей Викторович - магистрант второго года обучения кафедры высокомолекулярных соединений и коллоидной химии, Воронежский государственный университет

Быковский Дмитрий Владимирович - аспирант кафедры высокомолекулярных соединений и коллоидной химии, Воронежский государственный университет; тел.: +7(951) 8713126, e-mail: nasredinne@mail.ru
Vyacheslav A. Kuznetsov - Dr. Sci. (Chem.), Professor of Macromolecules Compounds and Colloid Chemistry Department, Voronezh State University; tel.:+7(920)4523733; e-mail: dr.v.kuznetsov@gmail. com

Maria S. Lavlinskaya - Cand. Sci. (Chem.), Junior Researcher of Molecular Biotechnology Department, Voronezh State University; tel.: +7(950) 7585216; email: maria.lavlinskaya@gmail.com

Andrey V. Sorokin - master student of the second year education of Macromolecules Compounds and Colloid Chemistry Department, Voronezh State University

Dmitriy V. Bykovskiy - post-graduate student of Macromolecules Compounds and Colloid Chemistry Department, Voronezh State University; tel.: +7(951) 8713126, e-mail: nasredinne@mail.ru 